\title{
Impacts du développement des biocarburants sur la production française de grandes cultures
}

\author{
Loic GUINDÉ*, Florence JACQUET**, Guy MILLET* \\ * UMR Economie publique, INRA, Thiverval-Grignon, France \\ ** Auteur correspondant : Economie publique, INRA, BP 01, 78850 Thiverval-Grignon, France \\ e-mail :fjacquet@grignon.inra.fr
}

\begin{abstract}
Résumé - Le papier analyse les conséquences de la politique de développement des biocarburants sur la production française de grandes cultures. Les simulations sont conduites à l'aide d'un modèle d'offre de biocarburants, construit à partir de modèles micro-économiques d'exploitations et d'un module de transformation des matières premières agricoles en biocarburants. Nous montrons qu'un objectif d'incorporation de $7 \%$ de biocarburants dans les carburants utilisés dans les transports routiers, s'il devait se réaliser sur la base d'une production agricole française sans réduire les exportations, conduirait à une croissance très importante de la superficie en colza, qui couvrirait alors, dans les principales régions de production, près de $30 \%$ des superficies cultivées. Une incorporation de $10 \%$ ne pourrait pas être atteinte sur la base d'une production nationale. Nous montrons également que le coût d'opportunité du colza augmenterait avec la demande et nous calculons les seuils de compétitivité du biodiesel par rapport au gazole, pour différents niveaux de prix du pétrole.
\end{abstract}

Mots-clés : biocarburant, politique énergétique, grande culture, France

Impacts of the French bio-fuel policy on the French arable crop sub-sector

Summary - The paper provides an analysis of the impacts of the bio fuel policy on the French arable crop subsector. The model used is a bio fuel supply model composed of an agricultural module and an industrial bio fuelprocessing module. Our results show that the incorporation target of $7 \%$ of bio fuels in transport fuels would lead to a considerable increase in the rapeseed area. In the main producing regions, the rapeseed area would reach approximately a third of the total farmed area. It would not be possible to reach a $10 \%$ incorporation target without imports. Furthermore, we analyse the impacts of reaching these production levels on the rapeseed opportunity costs, and show that reaching the incorporation targets will need an increase in rapeseed prices paid to farmers. We calculate the impacts of this opportunity cost increase on the competitiveness of bio fuels with respect to fossil oil, for different levels of oil prices.

Keywords: bio fuel, energy policy, agriculture, French arable crops

Descripteurs JEL : Q12, Q42, Q48 


\section{Introduction}

Le développement des biocarburants en Europe, aux Etats-Unis et dans plusieurs autres pays du monde constitue, au début des années 2000, un événement d'importance majeure pour l'économie agricole mondiale. Alors que jusqu'ici, seul le Brésil utilisait de manière importante un produit d'origine agricole comme carburant, l'éthanol de canne à sucre, l'Union européenne et les Etats-Unis décident de se lancer à leur tour dans cette voie, sur la base de soutiens publics importants. Les objectifs affichés sont pour l'Union européenne au nombre de trois: la lutte contre le réchauffement climatique par la diminution des émissions de dioxyde de carbone, la réduction de la dépendance du secteur des transports vis-à-vis du pétrole, et la création de nouvelles opportunités de revenu pour les agriculteurs. Ces deux derniers objectifs sont aussi ceux qui ont été mis en avant aux Etats-Unis et dans les autres pays, la question de la lutte contre le changement climatique étant variablement invoquée.

Des instruments de politique publique de différentes natures sont mis en place pour inciter au développement de cette nouvelle filière de production d'énergie : aides aux investissements, objectifs plus ou moins obligatoires d'incorporation de biocarburants dans les carburants traditionnels utilisés dans les transports routiers, avantages fiscaux pour les producteurs de carburants incorporant des biocarburants. En 2006, les Etats-Unis sont devenus le premier producteur mondial d'éthanol devant le Brésil. Au sein de l'Union européenne (UE), la production de biodiesel domine : l'UE produit $80 \%$ du biodiesel mondial.

Ce développement des biocarburants a suscité récemment de nombreux travaux d'évaluation économique et environnementale (pour une revue de littérature, voir notamment Rajagopal et al., 2007). Trois grands types de questions se posent. La première est celle des impacts du développement des biocarburants sur les prix et les marchés de produits agricoles et de biens alimentaires. Un des résultats des modèles prospectifs est que l'effet du développement des biocarburants sur les prix des produits agricoles devrait être important dans les années à venir (voir, en particulier, les travaux de l'IFPRI : Msangi et al., 2006; Von Braun, 2007; et pour les Etats-Unis, ceux de FAPRI : Elobeid et al., 2006 ; Tokgoz et al., 2007). La compétitivité des biocarburants pourrait cependant se trouver à terme menacée par l'accroissement des prix des matières premières engendré (Schmidhuber, 2007 ; Tokgoz et al., 2007). Pour l'Europe, la commission européenne (EC, 2007a) et l'OCDE (OCDE, 2006) indiquent que la réalisation des objectifs fixés pour 2010 aurait un impact particulièrement sensible sur les prix des oléagineux, des céréales et du sucre, ce que montre aussi Gohin (2007), qui met également en évidence l'ampleur de l'impact sur le revenu des agriculteurs.

Une seconde question est liée aux impacts environnementaux du développement des biocarburants. Les études utilisant la méthodologie de l'analyse du cycle de vie (ACV) montrent que les bilans en terme de réduction des émissions de gaz à effets de serre sont très dépendants des technologies utilisées et des filières, mais globalement positifs. Ils sont en général plus favorables pour le biodiesel et pour l'éthanol de canne à sucre que pour l'éthanol de céréales (Farell et al., 2006 ; Eucar/Concawe/JRC, 2006 ; Hill, 2007). On ne peut cependant pas attendre des 
biocarburants de première génération qu'ils contribuent de manière importante à la lutte contre le changement climatique compte tenu de leur potentiel limité de développement. Par ailleurs, d'autres travaux mettent aussi en exergue les effets environnementaux potentiellement négatifs liés aux changements dans les usages des sols, ou à l'intensification de la production agricole, changements qui ne sont pas pris en compte dans les ACV classiques (Curran et al., 2004 ; Doornbosch et Steenblik, 2007).

Enfin une troisième question concerne l'efficacité de la politique publique et des différents types d'instruments utilisés. Des travaux théoriques montrent que le bénéfice social global du soutien public aux biocarburants serait faible voire négatif, le gain des producteurs agricoles et des consommateurs de carburants ne compensant pas les pertes des consommateurs de biens alimentaires et des producteurs de pétrole (Rajagopal et al., 2007). Les politiques fiscales sont largement utilisées pour soutenir le développement des biocarburants au sein de l'UE comme aux Etats-Unis. Elles ne sont pas nécessairement les plus efficaces du point de vue de l'objectif recherché. D'autres politiques peuvent être proposées sur la base de soutiens variables en fonction du prix du pétrole (Tyner, 2007). L'efficacité des politiques au regard du soutien des revenus des agriculteurs et de leur effet sur les gains des pays exportateurs de biocarburants est également discutée (Gardner, 2007 ; De Gorter et Just, 2007).

Notre travail est centré sur l'analyse de l'impact de la politique française d'encouragement à la production de biocarburants sur l'agriculture française et, en particulier, sur le secteur des grandes cultures. En France comme en Europe, la production de biocarburants était jusqu'en 2003 essentiellement issue de la production de matières premières agricoles cultivées sur les terres mises en "jachère » à la suite de la réforme de la PAC de 1992. Récemment, la production de matières premières agricoles à des fins énergétiques s'est développée en concurrence avec celles à usages alimentaires. Un changement important dans la politique française a eu lieu en 2005, avec l'instauration d'une taxe pour les distributeurs de carburants pour les transports routiers qui n'incorporeraient pas une quantité de biocarburant au minimum égale à l'objectif fixé par les pouvoirs publics. Cette taxe très dissuasive a un effet quasiment identique à une obligation d'incorporation. Nous étudierons ici l'effet de cette obligation d'incorporation sur la production française de biocarburants sous l'hypothèse que cette dernière n'est réalisée qu'à partir de matières premières agricoles produites sur le sol français.

Dans la partie suivante, nous présentons le contexte actuel du développement des biocarburants et des cultures énergétiques en France, en insistant plus particulièrement sur le contexte réglementaire. Puis, dans la troisième partie, nous décrivons le modèle d'offre de biocarburants que nous avons utilisé, les scénarios construits et les résultats obtenus. Nous analysons les impacts que pourraient avoir les objectifs d'incorporation de biocarburants fixés par la France : d'une part, sur les assolements et la concurrence entre production énergétique et production alimentaire dans les exploitations françaises de grande culture ; d'autre part, sur la compétitivité des biocarburants par rapport aux carburants traditionnels. 


\section{Le contexte du développement des biocarburants en France}

\subsection{Quelques caractéristiques des filières biocarburants en France}

Les biocarburants utilisés en France sont actuellement du biodiesel pour les trois quarts et pour un quart de l'éthanol. Le biodiesel, ou ester méthylique d'huile végétale (EMHV), est obtenu à partir d'huile végétale par transesterification avec du méthanol. Les huiles utilisées sont en Europe principalement de l'huile de colza et, dans une moindre mesure (moins de $20 \%$ ), de l'huile de tournesol et des huiles importées (palme, soja). Le bioéthanol est produit par fermentation des sucres contenus dans les plantes sucrières (betterave, canne à sucre) ou amylacées (blé, maïs, orge), puis déshydratation. En France, les deux tiers du bioéthanol proviennent de la betterave, le reste est produit à partir de céréales et d'alcool vinique.

L'éthanol est principalement incorporé dans l'essence sous forme d'ETBE (ethyl tertio butyl éther) qui résulte d'une synthèse entre de l'éthanol et de l'isobutylène. L'ETBE contient 49,75\% en masse (47\% en volume) d'éthanol. L'incorporation d'ETBE présente des avantages techniques (faible volatilité, indice d'octane élevé, tolérance à l'eau).

Le développement de la filière biodiesel est bien plus important que celui de la filière bioéthanol. Ceci s'explique notamment par la part beaucoup plus importante du gazole (73\% en 2006) par rapport à l'essence (27\%) dans le marché français des carburants destinés au transport routier. Cette part devrait s'accroître dans les années à venir, compte tenu de la diésélisation croissante du parc automobile. La France importe aujourd'hui environ le tiers de sa consommation de gazole alors que l'essence est produite en excédent (DIREM, 2006).

\subsection{Le contexte réglementaire}

Le développement des biocarburants en France a largement été guidé par les incitations mises en place par les pouvoirs publics, à la fois, dans le secteur agricole et dans le secteur de l'énergie. Ce développement provient ainsi d'une politique agissant à la fois sur l'offre des agriculteurs en matières premières et sur la demande des distributeurs de carburants. La politique agricole commune (PAC) stipule les modalités par lesquelles les agriculteurs français reçoivent des aides pour produire des cultures à usage energétique. La consommation de biocarburants fait également l'objet d'une politique européenne, mais sous forme de directives et ce sont donc les Etats-Membres qui définissent les modalités spécifiques des politiques. Les instruments de cette politique sont en France: une défiscalisation partielle par réduction de la taxe intérieure à la consommation (TIC) appliquée aux biocarburants par rapport aux carburants traditionnels et une exonération de la taxe générale sur les activités polluantes (TGAP) payée par les distributeurs de carburants, en cas d'incorporation de biocarburants.

\subsubsection{Cultures énergétiques sur jachère et aides aux cultures énergétiques}

En 1992, la réforme de la PAC instaure, pour réduire les excédents de production agricole, l'obligation pour les agriculteurs de laisser une partie de leurs terres hors 
production, les agriculteurs percevant alors une prime sur les hectares ainsi mis en jachère. Sur cette " jachère PAC ", seules les cultures à usage non alimentaire sont autorisées, en particulier celles destinées aux biocarburants. En 2003, une autre réforme de la PAC introduit une nouvelle incitation à la production de biocarburants sous forme d'une aide spécifique aux cultures énergétiques (ACE) de 45 euros/ha pour les cultures à usage énergétique qui sont produites hors jachère. Cette aide a pour but d'orienter une plus grande partie des cultures oléagineuses, sucrières et céréalières vers la production de biocarburants. Elle est attribuée aux agriculteurs ayant souscrit des contrats avec des industriels. Un plafond de 1,5 million d'hectares pouvant bénéficier de cette aide est fixé pour l'UE. Pour 2007, cette limite est portée à 2 millions d'hectares. Néanmoins, le dépassement de cette superficie maximale $(2,84$ millions d'hectares en 2007) a conduit en 2008 à une diminution proportionnelle, soit de $30 \%$, du montant de l'aide.

\subsubsection{Réduction de la TIC et exonération de la TGAP}

La France avait obtenu, dès 1992, l'autorisation d'appliquer des taux différenciés de droits d'accise sur les biocarburants par rapport aux produits pétroliers afin d'accompagner le développement de la production de biocarburants issue des cultures produites sur la jachère. Cependant, c'est en 2003 que se définit une politique européenne sur les biocarburants. Deux directives constituent le cadre de cette politique. La directive sur la promotion des biocarburants (Directive 2003/30/EC) fixe les objectifs à atteindre ${ }^{1}(2 \%$ de biocarburants dans les carburants destinés au transport routier en 2005, 5,75\% en 2010). La directive sur la taxation de l'énergie (Directive 2003/96/EC) autorise les Etats-Membres à mettre en place des mesures de réduction ou d'exonération fiscale sur les biocarburants pour encourager leur utilisation. Les objectifs fixés sont seulement indicatifs et, par conséquent, le développement des biocarburants qui s'observe dès lors dans les pays membres dépend largement des politiques nationales mises en place et des stratégies des acteurs économiques.

En France, le premier instrument de cette politique est une défiscalisation partielle, sous forme de réduction de la taxe intérieure sur la consommation (TIC, ex TIPP, taxe intérieure sur les produits pétroliers). Cette défiscalisation est accordée aux biocarburants afin de compenser le surcoût des biocarburants par rapport aux carburants traditionnels. Elle est attribuée pour des volumes limités aux unités de production ayant reçu un agrément après un appel d'offre communautaire (cf. tableau 1).

La politique française de promotion de l'usage des biocarburants s'est considérablement renforcée à partir de 2005, en fixant des objectifs plus ambitieux que ceux fixés au niveau européen (loi 2005-781 du 13 juillet 2005 modifiée par la loi d'orientation agricole 2006-11 du 5 janvier 2006). L'objectif européen d'incorporation

\footnotetext{
${ }^{1}$ Les objectifs d'incorporation des biocarburants dans les carburants sont définis en valeur énergétique. Mesurée par le pouvoir calorifique inférieur (PCI), cette valeur énergétique est plus faible pour les biocarburants que pour les carburants classiques (elle est de $92 \%$ pour le biodiesel, $66 \%$ pour l'éthanol, relativement à celle du carburant de référence).
} 
Tableau 1. Agréments attribués et prévus (en milliers de tonnes) en France

\begin{tabular}{lrrr}
\hline & EMHV & ETBE & Ethanol \\
\hline 2004 & 401 & 99 & 12 \\
2005 & 417 & 130 & 72 \\
2006 & 677 & 169 & 137 \\
2007 & 1343 & 225 & 337 \\
2008 & 2478 & 225 & 717 \\
2009 & 2728 & 225 & 867 \\
2010 & 3178 & 225 & 867 \\
\hline
\end{tabular}

Source : ministère de l'Industrie, 2007.

de $5,75 \%$ pour 2010 est avancé à 2008 pour la France et les objectifs de $7 \%$ pour 2010 et $10 \%$ pour 2015 sont fixés. Les volumes d'agréments attribués permettent d'atteindre ces objectifs.

Les niveaux de défiscalisation sont ajustés annuellement pour tenir compte des conditions du marché. Le niveau de la défiscalisation était, en 2004 et 2005 , de $33 € / h \mathrm{hl}$ pour l'EMHV, et de $38 € / \mathrm{hl}$ pour l'éthanol. Il a été réduit, une première fois en 2006 , à $25 € /$ hl pour l'EMHV et à $33 € / h$ l pour l'éthanol, puis de nouveau, début 2008 , où les montants ont été fixés à $22 € /$ hl pour le biodiesel et à $27 € /$ hl pour l'ETBE.

En 2005, a également été mise en place une modification du système de taxation des carburants (loi de finances 2005) par l'instauration d'une nouvelle composante de la taxe générale sur les activités polluantes (TGAP). Cette TGAP s'applique aux carburants routiers ne respectant pas un taux minimum d'incorporation de biocarburants. Les distributeurs (raffineurs, grandes surfaces, indépendants) qui mettent à la consommation des carburants contenant une proportion de biocarburants inférieure aux objectifs nationaux doivent acquitter cette taxe.

Le taux de la taxe que doit payer un distributeur de carburants est diminué à proportion des quantités de biocarburants qu'il incorpore dans les carburants. Les taux ont été fixés par année (tableau 2). Comme on peut le constater, chaque année ce taux est égal à l'objectif d'incorporation que s'est donné le gouvernement français. Ainsi un distributeur qui incorpore des biocarburants à hauteur de l'objectif national annuel ne payera pas cette TGAP. Etant donné le niveau élevé de la TGAP, cette mesure est très fortement incitative.

Tableau 2. Taux de la TGAP appliquée sur les carburants fossiles

\begin{tabular}{ll}
\hline & Taux \\
\hline 2006 & $1.75 \%$ \\
2007 & $3.50 \%$ \\
2008 & $5.75 \%$ \\
2009 & $6.25 \%$ \\
2010 & $7.00 \%$ \\
\hline
\end{tabular}

Source : bulletin officiel des douanes, 2006 
Les nouveaux biocarburants (l'ester éthylique d'huile végétale et le biodiesel de synthèse) bénéficient maintenant également de ces mesures de défiscalisation et d'exonération de la TGAP.

\subsection{Consommation et production de biocarburants, conséquences sur l'agriculture}

Jusqu'en 2003, en France, la production de biocarburants était essentiellement liée au développement des cultures à usage non alimentaire autorisées sur les terres en « jachère », suite à la réforme de la PAC de 1992. A partir de 2003, la production se développe en concurrence avec les productions alimentaires, mais le développement des biocarburants reste faible jusqu'en 2005, se traduisant en particulier par des niveaux d'incorporation dans les carburants en-deçà des objectifs fixés. En revanche, on constate à partir de 2006 un développement beaucoup plus fort de la production et de la consommation. Ainsi, en 2006, l'objectif fixé de 1,75\% d'incorporation de biocarburants a été faiblement dépassé, le niveau observé ayant atteint 1,76\% (1,77\% pour le gazole et $1,75 \%$ pour l'essence). Il semble que la nouvelle politique mise en place en 2005, en particulier la création du supplément TGAP, ait eu un effet incitatif important sur les comportements des industriels et des distributeurs.

\subsubsection{Production et consommation actuelles}

Les tableaux 3 et 4 ci-dessous présentent des données sur la production et la consommation françaises de biocarburants ainsi que sur les agréments attribués aux unités de transformation. Ces tableaux visent, d'une part, à comparer production et consommation domestiques de biocarburants, d'autre part, à mettre en perspective la production française de biocarburants avec la production de matières premières agricoles à des fins énergétiques issue des superficies aidées par la PAC. Les données rapportées par les tableaux 3 et 4 sont extraites de sources différentes et les écarts observés doivent être analysés avec prudence.

Dans chaque tableau, la première ligne donne une production «potentielle » du biocarburant considéré, calculée à partir des superficies agricoles déclarées en «cultures énergétiques» sur "jachère », d'une part, dans le régime "aides aux cultures énergétiques ", d'autre part (voir le détail en tableau 5). Ne disposant pas de données sur les échanges de biocarburants, on ne peut pas entièrement conclure sur le lien entre cette production «potentielle » et la production domestique « réelle».

En ce qui concerne le biodiesel (tableau 3), on constate que la production «potentielle » est supérieure à la production observée, laissant penser que l'industrie française s'est essentiellement fournie en matières premières agricoles produites sur le territoire français sur des superficies ayant bénéficié des aides de la PAC, et qu'une partie des superficies aidées a pu être contractualisée par des transformateurs situés hors de France. La situation française est, de ce point de vue, très différente de la situation de l'ensemble de l'Europe, où près de la moitié de la production de cultures énergétiques a été produite sur des surfaces hors jachère et hors ACE, c'est-à-dire à partir de matières premières agricoles ne bénéficiant pas de soutien public pour un 
Tableau 3. Production et consommation françaises d'EMHV (en milliers de tonnes)

\begin{tabular}{lccc}
\hline & 2004 & 2005 & 2006 \\
\hline Production calculée à partir des surfaces déclarées en « cultures énergétiques » & 388 & 650 & 798 \\
Production observée & 348 & 492 & 743 \\
Consommation & 324 & 368 & 631 \\
Agréments & 401 & 417 & 677 \\
\hline
\end{tabular}

Sources: ONIGC et nos calculs pour la production issue des surfaces aidées par la PAC (ONIGC, 2006); European Biodiesel Board, pour la production observée (bttp://www.ebb-eu.org/) ; ministère de l'Industrie pour la consommation et les agréments (Ministère de l'Industrie, 2007 ; Rapport France directive biocarburants, 2006)

Tableau 4. Production et consommation françaises d'éthanol, dont ETBE (en milliers de tonnes)

\begin{tabular}{lccc}
\hline & 2004 & 2005 & 2006 \\
\hline Production calculée à partir des surfaces déclarées en « cultures énergétiques » & 53 & 90 & 161 \\
Production observée* & 81 & 115 & 199 \\
Consommation & 39 & 57 & 118 \\
Agréments & 59 & 134 & 217 \\
\hline
\end{tabular}

Notes: *dont production issue d'alcool vinique dénaturé

Sources: ONIGC et nos calculs pour la production issue des surfaces aidées par la PAC; European Bioethanol Fuel Association pour la production observée (bttp://www.ebio.org); ministère de l'Industrie pour la consommation et les agréments.

usage en biocarburant (EC, 2007b). On remarque également que les quantités mises à la consommation sont légèrement inférieures au maximum défiscalisé, certaines usines ne remplissant pas entièrement le volume de production agréé.

En ce qui concerne l'éthanol, une partie de la production provient de l'alcool mis à l'intervention, dans le cadre du régime de distillation de l'organisation commune de marché $(\mathrm{OCM})$ du vin, et revendu aux unités de production d'éthanol. Le tableau 4 indique que la mise à la consommation totale de bioéthanol est relativement faible comparée à la production observée et aux quantités donnant droit à défiscalisation.

Les superficies agricoles qui ont été mobilisées pour la production de biocarburants en France (sur jachère et bénéficiant de l'aide aux cultures énergétiques) s'élevaient ainsi en 2004 à environ 300000 hectares. En 2006, elles en représentent plus du double, soit 766 milliers d'hectares. Il s'agit en grande majorité de colza, qui couvre $88 \%$ de ces surfaces. En 2006, la moitié des superficies cultivées pour produire des biocarburants le sont sur la « jachère PAC », l'autre moitié sur des terres où elles entrent en concurrence avec des usages alimentaires (ONIGC, 2006).

Ainsi, en 2006, près de la moitié de la superficie de colza cultivée en France est utilisée pour produire du biodiesel, alors que cet usage ne concerne que $8 \%$ des superficies en tournesol, $6 \%$ de celles en betterave et moins de $1 \%$ des superficies en blé (tableau 5). 
Tableau 5. Part des superficies agricoles françaises utilisées pour produire des biocarburants en 2006 (en milliers d'hectares)

\begin{tabular}{|c|c|c|c|c|c|c|}
\hline & Colza & Tournesol & Blé & Maïs & Betterave \\
\hline \multicolumn{2}{|c|}{ superficie totale } & 1406 & 645 & 4794 & 1502 & 379 \\
\hline \multicolumn{2}{|c|}{ superficie dédiée aux biocarburants } & 667 & 54 & 20 & 2 & 23 \\
\hline \multirow[t]{2}{*}{ Dont } & Jachère PAC & 314 & 38 & 17 & 2 & 9 \\
\hline & $A C E$ & 353 & 16 & 3 & & 14 \\
\hline \multicolumn{2}{|l|}{$\%$} & 47.5 & 8.3 & 0.4 & 0.1 & 6.0 \\
\hline
\end{tabular}

Sources: Agreste et ONIGC

Si le développement des biocarburants est aujourd'hui tout-à-fait modeste au regard de la quantité de carburants qu'il a permis de substituer, on voit ainsi qu'il tient déjà une place très importante dans les débouchés de certaines productions agricoles.

\subsubsection{Conséquences sur l'agriculture de la poursuite du développement des biocarburants}

Les objectifs fixés par le gouvernement français impliquent une accélération considérable du développement de l'usage des biocarburants dans les prochaines années. Les biocarburants de seconde génération ${ }^{2}$ représentent une perspective importante à cet égard. Cependant, la plupart des observateurs s'accordent à dire qu'il est peu probable qu'ils soient compétitifs avant 2015 (voir les avis dans les résultats de la consultation publique lancée en avril 2006 par la Commission européenne : European Commission, 2007c). Dans la suite de notre travail, nous nous intéresserons donc à la possibilité d'atteindre les objectifs fixés à partir des biocarburants actuels, de première génération.

Du point de vue des conséquences que ce développement des biocarburants pourrait avoir sur l'agriculture française, la différence est nette entre les filières oléagineuses, d'une part, et la production de betteraves et de céréales, d'autre part. Pour ces dernières, atteindre les objectifs de production d'éthanol annoncés peut s'envisager sans impacts majeurs sur les assolements. Dans une hypothèse où la production d'éthanol serait assurée à $80 \%$ par des céréales et à $20 \%$ par la betterave à sucre, nous pouvons calculer que pour atteindre $10 \%$ d'incorporation en 2015 , il serait nécessaire de mobiliser 42000 ha de betteraves et 490000 ha de blés, soit respectivement $11 \%$ et $10 \%$ des superficies cultivées dans ces deux cultures. La production d'éthanol de betterave peut permettre de maintenir la production française de betteraves à un niveau proche de ce qu'elle est actuellement et compenser, en quelque sorte, les effets de la mise en œuvre de la réforme de l'OCM sucre. La production d'éthanol de céréales pourrait se faire au détriment d'une partie des exportations céréalières actuelles sur pays

\footnotetext{
${ }^{2}$ Les biocarburants de seconde génération désignent les biocarburants (éthanol, biodiesel) qui pourraient être produits à partir de biomasse ligno-cellulosique (bois, paille, plantes entières, etc.). Les procédés sont actuellement au stade expérimental (pour plus de détails sur ce point, $c f$. Gosse et Cormeau, 2007).
} 
tiers, et certainement aussi par une remise en culture d'une partie des terres en jachère ${ }^{3}$.

En ce qui concerne les oléagineux, la situation est différente, les objectifs d'incorporation en biodiesel nécessitant des quantités d'huiles considérables par rapport à la production française actuelle. Sur la base d'un biodiesel produit à $90 \%$ à partir d'huile de colza et à $10 \%$ à partir d'huile de tournesol, et sous les hypothèses :

- d'un rendement de 3,7 t/ha pour le colza et 2,47 t/ha pour le tournesol en 2015 (3,5 t/ha et $2,4 \mathrm{t} /$ ha en 2010$)$;

- d'un maintien à leurs niveaux actuels des superficies de colza et de tournesol cultivées à des fins alimentaires d'une part, des exportations de graines et d'huiles de ces deux produits d'autre part,

nous pouvons estimer l'accroissement des superficies cultivées en colza et tournesol qui serait requis pour produire la quantité d'huiles nécessaire pour atteindre les objectifs d'incorporation de biodiesel fixés par la France. Les résultats de ces calculs sont rapportés dans le tableau 6.

Ainsi, il apparaît qu'entre 2006 et 2015 l'objectif de $10 \%$ d'incorporation impliquerait un doublement de la superficie totale en oléagineux.

Plusieurs questions se posent face à cette croissance attendue. Si la demande de biodiesel devait être satisfaite sur la base d'une production réalisée à partir de matières premières produites en France, quelles seraient les régions de France concernées par l'augmentation de la production d'oléagineux? Comment les agriculteurs vont-ils modifier leurs systèmes de cultures? Quel sera le prix du colza auquel ils seront prêts à produire la quantité de colza nécessaire pour produire les quantités requises de biodiesel? Quel sera l'impact de ce changement de prix sur la compétitivité du biodiesel?

Ces questions sont celles que nous traitons dans la suite de notre article. Pour cela, nous simulons l'impact du développement de la production de biocarburants sur le

Tableau 6. Superficies nécessaires pour atteindre $7 \%$ d'incorporation de biodiesel en 2010 et $10 \%$ en 2015 (milliers d'hectares)

\begin{tabular}{lccc}
\hline & Observée 2006 & Calculée 2010 & Calculée 2015 \\
\hline Superficie totale en oléagineux & 2094 & 3139 & 3984 \\
Dont & & & \\
pour la production de biodiesel & 720 & 1809 & 2654 \\
Autres utilisations intérieures & 630 & 630 & 630 \\
Exportations & 700 & 700 & 700 \\
\hline
\end{tabular}

Sources : nos calculs à partir de ONIGC, Agreste

3 En 2006, la superficie en jachère s'élevait en France à 1,3 million d'hectares dont 380000 ha cultivés à des fins non alimentaires. Le Conseil des ministres de l'Agriculture de l'UE du 26 septembre 2007 a décidé de supprimer l'obligation de mise en jachère pour la campagne 2007/ 2008. 
secteur des grandes cultures, à l'aide d'un modèle micro-économique d'offre agricole, basé sur la représentation d'un échantillon d'exploitations françaises spécialisées en grandes cultures. Nous nous intéressons en particulier à deux aspects: i) les conséquences de la demande de matières premières agricoles pour la production de biocarburants sur les assolements et, en particulier, sur la place du colza dans ceux-ci, ii) les prix des oléagineux (colza et tournesol) qu'il sera nécessaire d'atteindre pour inciter les agriculteurs à produire les quantités suffisantes de matières premières et l'impact de ces prix sur la compétitivité du biodiesel par rapport au gazole.

\section{Simulations de l'impact du développement des biocarburants}

\subsection{Présentation du modèle}

Le modèle "OSCAR » a été développé dans le but d'analyser les impacts des réformes des politiques agricoles et des politiques de soutien aux biocarburants sur les exploitations françaises de grandes cultures. OSCAR est composé d'un modèle d'offre agricole basé sur des données micro-économiques et d'un module de transformation industrielle des productions agricoles en biocarburants liquides.

\subsubsection{Principales caractéristiques du modèle}

Le modèle d'offre agricole maximise le revenu net global des producteurs agricoles, sous des contraintes techniques et agronomiques définies au niveau des exploitations. Le module de transformation industrielle s'appuie sur les coûts de transformation ainsi que les coefficients techniques de transformation des matières premières agricoles en biocarburants et co-produits.

Ce modèle, déjà utilisé dans de précédents travaux (Sourie et al., 2005 ; Rozakis et Sourie, 2005), a été mis à jour avec les données du RICA (Réseau d'information comptable agricole) 2004. Le modèle est construit sur la base d'une agrégation de modèles individuels d'exploitations spécialisées en céréales et grandes cultures (orientations technico-economiques, OTEX 13 et 14 du RICA). Le modèle agrège l'offre globale de ces exploitations en tenant compte de la représentativité de chacune. La fonction objectif du modèle est donc la somme pondérée (par les coefficients de représentativité) de la marge brute de chaque exploitation. Rappelons qu'en 2004, le RICA France comprend au total 7330 exploitations qui représentent 383069 exploitations professionnelles. Les OTEX 13 «céréales et oléagineux » et 14 «cultures générales" comprennent au total 1872 exploitations représentant 84429 exploitations de grandes cultures (Agreste, 2006).

Un modèle d'estimation des marges permet de déduire des données individuelles du RICA et des données de la «sonde Grande Culture » du RICA ${ }^{4}$, les marges par

\footnotetext{
${ }^{4} \mathrm{La}$ « sonde Grande Culture » est une enquête faite auprès des exploitations agricoles spécialisées en grande culture faisant partie du RICA, localisées dans les régions Ile-de-France, Centre et MidiPyrénées. Cette enquête recueille les charges et les produits pour chaque culture, ces données n'étant pas désagrégées par culture dans le RICA.
} 
cultures pour chaque exploitation (Guindé et al., 2004). La procédure d'estimation des marges au niveau individuel oblige à restreindre l'échantillon d'exploitations retenues pour la modélisation par rapport à l'échantillon global des exploitations des OTEX 13 et $14 \mathrm{du}$ RICA, en éliminant les exploitations ayant une trop grande proportion de cultures spéciales dans leur assolement. Ainsi, notre échantillon de travail comprend 1094 exploitations sur les 1872 contenues dans le RICA. Les coefficients de pondération des exploitations de notre modèle sont issus des coefficients de pondération du RICA et ont été modifiés afin de garder à notre échantillon le niveau de représentativité par rapport à la France de l'OTEX 13 et 14.

Environ 75000 exploitations sont ainsi représentées, qui produisent (en 2004) $66 \%$ de la production de blé française, $88 \%$ de la production de betteraves et $74 \%$ de la production de colza.

\subsubsection{Représentativité de l'échantillon}

L'attention particulière que nous accorderons à la production de colza dans l'analyse de nos résultats nous conduit à préciser les caractéristiques de notre échantillon à cet égard. Dans le tableau 7 , on constate que neuf régions concentrent $83 \%$ des exploitations qui produisent du colza.

L'analyse des effets régionaux des scénarios simulés sera donc concentrée sur ces neuf régions. Les caractéristiques de notre modèle font que, pour chaque exploitation, seules seront "possibles» dans nos simulations les activités observées en 2004. Autrement dit, seules les exploitations qui produisaient du colza en 2004 en produiront dans les différents scénarios, ce qui peut être considéré comme une des limites de notre modèle. Mais on observe également dans le tableau 7 que, dans les régions considérées, la plus grande part des exploitations produisait déjà du colza en 2004.

Tableau 7. Nombre d'exploitations produisant du colza et répartition régionale

\begin{tabular}{lccc}
\hline \multicolumn{1}{c}{ RICA 2004 - OTEX13-14 } & Exploitations représentées & $\begin{array}{c}\text { Dont exploitations } \\
\text { ayant du colza }\end{array}$ & $\%$ \\
\hline Centre & 11918 & 9828 & 82 \\
Champagne & 6740 & 5397 & 80 \\
Picardie & 7041 & 4156 & 59 \\
Poitou- Charentes & 5724 & 3573 & 62 \\
Bourgogne & 4244 & 3508 & 83 \\
IDF & 3262 & 2526 & 77 \\
Haute-Normandie & 2570 & 1677 & 65 \\
Lorraine & 1638 & 1638 & 100 \\
Nord-Pas-de-Calais & 4271 & 1479 & 35 \\
TOTAL 9 régions & 47408 & 33782 & \\
Total France & 74827 & 40632 & \\
$\%$ & 63 & 83 & \\
\hline
\end{tabular}




\subsubsection{Contraintes d'assolement et nouvel itinéraire technique pour le colza}

Les contraintes agronomiques sont modélisées sous la forme d'un pourcentage maximum de certaines cultures dans l'assolement. Ces pourcentages sont issus des observations en 2004. Sont incluses les contraintes suivantes: un maximum de $30 \%$ de la superficie est cultivable en betterave, $15 \%$ en protéagineux, $30 \%$ en tournesol.

Concernant le colza, $80 \%$ des exploitations qui en cultivaient avaient, en 2004, moins de $25 \%$ de leurs surfaces cultivées en colza. Les $20 \%$ restants avaient une plus grande proportion de colza dans leurs assolements. Afin de simuler l'impact que pourrait avoir le développement du biodiesel sur la place du colza dans les successions de cultures, nous avons introduit dans le modèle deux «techniques » de production. La première, le «colza $A$ » correspond à une culture dont le retour dans la succession de cultures est inférieur à une année sur quatre. La place de cette culture dans l'assolement est donc limitée à $25 \%$ de la surface au maximum. Une seconde technique (le « colza B ») a été introduite, qui correspond à un retour plus fréquent du colza (une année sur deux ou sur trois) dans la succession de cultures, pratique dont on peut penser qu'elle pourrait se développer dans un contexte de demande accrue en biocarburants. La contrainte globale sur la superficie totale en colza dans chaque exploitation spécifie que celle-ci (la somme des superficies en "colza $A$ » et en « colza B ») peut couvrir jusqu’à $40 \%$ de la superficie totale cultivée.

La pratique «colza $B$ » suppose un nouvel itinéraire technique avec un recours plus important aux engrais azotés et aux pesticides, et une diminution du rendement. En effet, lorsque l'on diminue le délai de retour du colza, la flore adventice devient difficile à contrôler et certaines maladies se trouvent favorisées (comme le herni, le phoma ou le sclérotinia, voir CETIOM, 2002). Par ailleurs, certaines résistances aux fongicides (notamment aux carbendazimes) peuvent apparaitre, rendant ainsi la lutte contre le sclérotinia plus difficile et nécessitant alors l'association de plusieurs matières actives. Concernant l'impact de la diminution du délai de retour sur le rendement, un facteur de réduction (FR) par rapport à une situation de référence optimale peut être estimé. Ce FR a été évalué à - $20 \%$ sur la base des travaux disponibles (Lefevre, 2005) et des experts interrogés. Nous avons, sur la base des mêmes sources, estimé l'augmentation des charges de cet itinéraire à $95 € /$ ha.

\subsubsection{Année de base et validation}

Notre modèle a été validé sur l'année 2004 sur la base des données agrégées de notre échantillon. Le tableau ci-dessous présente les résultats du modèle et les données observées, pour la totalité de l'échantillon et pour l'année 2004, en termes de surface allouée à chaque culture.

La solution du modèle est assez proche de la répartition observée des surfaces par culture. On observe cependant une répartition peu satisfaisante entre céréales à pailles, avec une surreprésentation du blé au détriment de l'orge, ainsi qu'une légère surestimation des surfaces en colza au détriment du tournesol. La répartition entre blé et orge n'influe pas sur les résultats de scénarios d'évolution de la production de biodiesel. La surestimation des surfaces en colza et tournesol est d'environ $1 \%$ de la surface totale en culture. Elle ne modifie donc pas fondamentalement les résultats du modèle. 
Tableau 8. Comparaison entre solutions du modèle et données observées

\begin{tabular}{|c|c|c|}
\hline en milliers d'ha & Observé 2004 & Modèle 2004 \\
\hline Blés & 3236 & 3681 \\
\hline Blés alimentaires & 3227 & 3663 \\
\hline Blé éthanol & 10 & 18 \\
\hline Orges & 967 & 540 \\
\hline Maïs & 1026 & 982 \\
\hline Betterave totale & 314 & 304 \\
\hline Betterave Sucre & 310 & 295 \\
\hline Betterave éthanol & 4 & 9 \\
\hline Colza total & 917 & 1111 \\
\hline Colza alimentaire & 729 & 890 \\
\hline Colza ester & 187 & 221 \\
\hline Pois & 294 & 294 \\
\hline Tournesol total & 426 & 311 \\
\hline Tournesol alimentaire & 416 & 232 \\
\hline Tournesol ester & 10 & 79 \\
\hline Jachère & 569 & 554 \\
\hline Autres & 374 & 311 \\
\hline TOTAL & 8122 & 8089 \\
\hline
\end{tabular}

\subsection{Hypothèses et scénarios}

Le modèle fonctionne sous trois hypothèses importantes qu'il convient de préciser à ce stade car elles constituent des limites importantes à notre analyse. Tout d'abord, il est supposé que, quel que soit le niveau de production et de consommation françaises de biocarburants, il n'y a pas de changement notable des flux d'échange de biocarburants entre la France et ses partenaires. En second lieu, l'hypothèse est faite que la production française de biocarburants est réalisée à partir de matières premières agricoles produites sur le territoire français uniquement. En d'autres termes, quel que soit le niveau de production de biocarburants, il n'y a pas de changement notable des importations françaises de matières premières agricoles pouvant être utilisées dans la fabrication de ces biocarburants. Enfin, il est supposé que, quel que soit le niveau de production et de consommation françaises de biocarburants, il n'y a pas de changement notable de la consommation alimentaire domestique et des exportations de matières premières agricoles pouvant être utilisées dans la fabrication de biocarburants. Autrement dit, lorsque la production de biocarburants augmente (du fait d'un accroissement de l'objectif d'incorporation), la totalité du supplément de demande induit de matières premières agricoles est traduite dans le modèle d'offre agricole en supplément d'offre requis de ces mêmes matières premières.

Ainsi, le modèle est utilisé en forçant le secteur des grandes cultures 5 à produire les quantités de matières premières agricoles nécessaires pour fabriquer les volumes de biocarburants requis pour atteindre les taux d'incorporation de biocarburants dans les

5 Dans le modèle, les quantités de matières premières agricoles demandées par le secteur de la transformation en biocarburants sont corrigées du poids de l'échantillon du RICA dans la production agricole française correspondante. 
carburants utilisés dans les transports routiers fixés par les pouvoirs publics. Nous obtenons ainsi pour différents niveaux d'objectif d'incorporation les conséquences sur les superficies cultivées dans les différentes régions de production françaises.

Les prix sont exogènes à l'exception des prix du colza et du tournesol (alimentaires et énergétiques) ainsi que de ceux des blés et betteraves à usages énergétiques. Pour ceux-ci, la valeur duale des contraintes de production, qui obligent à produire les quantités requises pour atteindre les taux d'incorporation fixés, nous renseigne sur le coût d'opportunité (ou shadow price) de la culture considérée. En d'autres termes, ces coûts d'opportunité de chaque culture correspondent aux prix qu'il faudrait payer aux producteurs français pour que ces derniers produisent exactement les quantités requises. En faisant varier les taux d'incorporation et, par suite, les quantités requises de matières premières agricoles, il est possible de reconstituer des courbes d'offre de chacune des cultures utilisées dans la fabrication de biocarburants ( $c f$. graphique 1 pour le colza).

L'horizon des simulations est 2015. Le tableau 9 ci-dessous reprend l'ensemble des hypothèses générales adoptées dans les différents scénarios simulés. Les tableaux 10 et 11 rapportent les caractéristiques des quatre scénarios simulés et de leurs variantes.

Les hypothèses générales présentées dans le tableau 9 concernent l'ensemble des scénarios, c'est-à-dire le scénario de référence et les scénarios simulés S1, S2, S3, S4.

Les réformes de la PAC qui sont en cours d'application ont été introduites: compromis de Luxembourg, réforme de l'OCM sucre de 2006. Aucune nouvelle réforme de la PAC n'a été envisagée. L'aide spécifique aux cultures énergétiques de

Figure 1. Offre de colza-ester et prix « dual » du colza

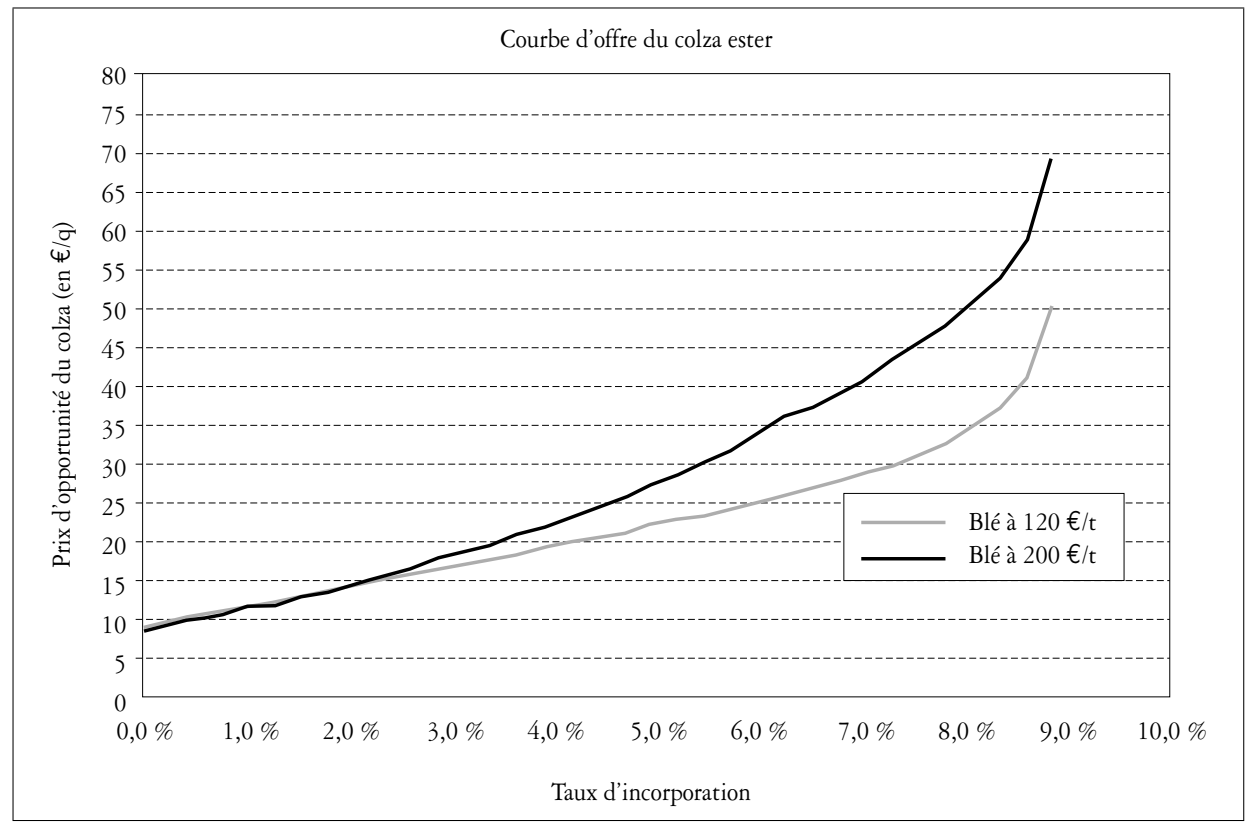


Tableau 9. Hypothèses générales

\begin{tabular}{|c|c|}
\hline & Hypothèses \\
\hline Politique agricole commune & $\begin{array}{l}\text { Réforme OCM sucre appliquée, ACE maintenue à } 45 € / \text { ha, } \\
\text { taux de jachère maintenu à } 10 \%\end{array}$ \\
\hline Rendements agricoles (en tonnes/ha) & $\begin{array}{l}\text { Estimés pour } 2015 \text { par exploitation. En moyenne (tonnes/ha) : } \\
\text { Blé : 7,91; colza 3,71; tournesol : 2,45; betterave : } 85,22\end{array}$ \\
\hline $\begin{array}{l}\text { Consommation de carburants dans les } \\
\text { transports routiers }\end{array}$ & 45,5 millions de tonnes équivalent pétrole \\
\hline Taux de change & $1,4 \$ / €$ \\
\hline $\begin{array}{l}\text { Eléments de calcul du prix de revient } \\
\text { du biodiesel }\end{array}$ & $\begin{array}{l}\text { Prix du méthanol } 300 € / \mathrm{t} \text {, autres coûts de transformation } \\
150 € / \mathrm{t} \text { (hors matière première), glycérine } 180 € / \mathrm{t} \text {, } \\
\text { tourteau de colza } 110 € / \mathrm{t} \text {. }\end{array}$ \\
\hline Taux d'incorporation éthanol & $7 \%$ \\
\hline Composition des biocarburants & $\begin{array}{l}\text { Biodiesel : maximum } 20 \% \text { de tournesol } \\
\text { Ethanol : } 80 \% \text { de blé, } 20 \% \text { de betterave }\end{array}$ \\
\hline
\end{tabular}

Tableau 10. Scénarios

\begin{tabular}{lccccc}
\hline & Sref & S1 & S2 & S3 & S4 \\
\hline Taux d'incorporation du biodiesel & $1,77 \%$ & $5,75 \%$ & $7 \%$ & $9 \%$ & $10 \%$ \\
Quantités incorporées en milliers de tonnes & & & & & \\
EMHV & 631 & 2050 & 2495 & 3208 & 3565 \\
En équivalent Huile & 674 & 2189 & 2665 & 3427 & 3808 \\
En équivalent Graines & 1653 & 5371 & 6538 & 8406 & 9340 \\
\hline
\end{tabular}

Tableau 11. Variantes

\begin{tabular}{|c|c|c|}
\hline Prix des céréales & Variante $\mathrm{P} 1$ : hypothèse générale & Variante P2 \\
\hline & Prix du blé : $120 € /$ tonne & $\begin{array}{l}\text { Prix du blé : } 200 € / \text { tonne } \\
\text { Prix des autres céréales : prix hypothèses } \\
\text { générales } \times 1,7\end{array}$ \\
\hline \multirow[t]{2}{*}{$\begin{array}{c}\text { Consommation } \\
\text { alimentaire domestique } \\
\text { et exportations }\end{array}$} & Variante $\mathrm{E} 1$ : hypothèse générale & Variante E2 \\
\hline & $\begin{array}{l}\text { Les quantités de colza et de tournesol } \\
\text { destinées à un usage alimentaire et à } \\
\text { l'exportation sont maintenues à leur } \\
\text { niveau observé en } 2004 \text { : équivalent } \\
\text { à } 934 \text { milliers de tonnes d'EMHV. }\end{array}$ & $\begin{array}{l}\text { Les quantités de colza et de } \\
\text { tournesol destinées à un usage } \\
\text { alimentaire et à l'exportation sont mises } \\
\text { à } 0: \text { la totalité de la production française } \\
\text { de colza et de tournesol est utilisée } \\
\text { à la fabrication de biodiesel. }\end{array}$ \\
\hline
\end{tabular}

45 euros/ha a été maintenue pour une superficie limitée à 460000 ha (calculée pour la France sur la base de la superficie de 1,5 million d'ha pour l'UE, au prorata de la part de la France dans la superficie européenne en céréales et oléagineux). Un taux de jachère obligatoire de $10 \%$ a été maintenu (l'impact de la suppression de cette mesure a été testée). L'évolution des rendements des productions agricoles a été estimée sur la base 
des observations 1990-2004. Le rendement de chaque culture pour chaque exploitation est projeté à l'horizon 2015, à partir de l'année de référence 2004, corrigée des aléas climatiques, en tenant compte du progrès technique observé en moyenne sur la période 1990-2004. La consommation de carburants dans les transports routiers retenue pour 2015 est de 45,5 millions de tonnes (Commission européenne, 2007 et 2003). La quantité maximale d'huile de tournesol pouvant être introduite dans le biodiesel est de $20 \%$, le reste étant fourni par l'huile de colza. La répartition entre éthanol de blé et éthanol de betterave est fixe, elle est de $30 \%$ pour le blé et $70 \%$ pour la betterave dans l'année de base, puis fixée à $80 \%$ pour le blé et $20 \%$ pour la betterave dans les simulations.

La part de la matière première agricole représente plus de $95 \%$ du coût final du biodiesel (une fois déduite la valorisation des tourteaux). L'évolution du prix des matières premières agricoles influence donc fortement le prix de revient du biodiesel. Le prix du tourteau est également un élément important. La Commission européenne prévoit une baisse de $56 \%$ du prix du tourteau de colza pour un niveau d'incorporation à $7 \%$ (CE, 2007) tandis que Gohin (2007) prévoit une baisse de $15 \%$, soit un prix à $110 € / t$ pour un niveau d'incorporation de $5,75 \%$. Nous avons retenu ici un prix de $110 € / t$. Nous avons testé la sensibilité de nos résultats à ce prix.

Nous centrons notre analyse sur l'impact de la croissance des quantités produites de biodiesel sur le secteur français des grandes cultures. Ainsi, dans tous les scénarios, nous fixons la quantité d'éthanol à produire au niveau requis pour atteindre un taux d'incorporation dans l'essence de $7 \%$ et nous simulons les impacts sur la production agricole de l'évolution de la quantité produite de biodiesel selon les différents taux d'incorporation considérés. Nous augmentons de manière progressive la quantité de biodiesel produite jusqu'à atteindre la quantité correspondant à un taux d'incorporation de $10 \%$. Les volumes de biodiesel correspondant aux différents taux d'incorporation considérés sont présentés dans le tableau 10. La sensibilité des résultats du modèle à des volumes de production d'éthanol correspondant à des taux d'incorporation dans l'essence variant de 1 à $10 \%$ a été testée.

Les prix des produits agricoles exogènes au modèle ont été fixés sur la base de résultats de simulations, à l'horizon 2015, de scénarios proches de ceux retenus ici, mais appliqués à l'UE à 15, issus du modèle GOAL (Gohin, 2007). Le prix du blé obtenu dans ce travail est de $120 € / t$, c'est celui que nous avons utilisé ici, ainsi que les prix des autres céréales et des protéagineux. Les prix du colza et du tournesol sont déterminés par notre modèle. Nous avons fait l'hypothèse que le prix auquel est rémunéré le colza à usage énergétique est le même que le prix du colza alimentaire, déduction faite de l'aide aux cultures énergétiques (ACE).

Nous avons fait une seconde simulation avec un nouveau vecteur de prix afin de tenir compte des conséquences d'une augmentation possible des prix des céréales. Nous avons retenu un prix du blé de $200 € / t$, soit 1,7 fois le prix actuel et appliqué cette croissance aux prix exogènes des autres cultures. Les résultats sur la compétitivité du biodiesel seront présentés pour ces deux variantes P1 et P2.

Nous avons vu (tableau 6) que les exportations et les utilisations en alimentation humaine représentent actuellement des débouchés importants de la production 
française d'oléagineux (l'équivalent des deux tiers des superficies). L'augmentation de la production agricole liée au développement du biodiesel dépend donc largement des hypothèses que l'on peut faire sur le maintien ou non des exportations et sur la substitution d'autres huiles dans la consommation alimentaire. Les droits de douanes sur les importations de biodiesel et les huiles végétales à l'entrée du marché européen sont actuellement bas (de 0 à $6 \%$ ad-valorem). Les importations sont cependant faibles (l'huile de palme entre pour environ $5 \%$ de la production européenne de biodiesel actuellement), car des contraintes et normes techniques s'opposent actuellement à l'utilisation d'autres huiles que celle de colza. On ne peut cependant pas exclure que de telles importations se développent à l'avenir, en provenance d'Asie du Sud-Est (huile de palme) ou d'Amérique (soja). Les débouchés actuels des exportations françaises d'oléagineux devraient se maintenir du fait de l'ampleur des programmes de développement dans les autres pays européens, en Allemagne en particulier. Nous avons donc considéré deux variantes, la première (E1) correspond au maintien des exportations et usages alimentaires au niveau atteint en 2004, l'autre (E2) à la suppression des exportations et usages alimentaires.

En 2004, la quantité d'huile de colza utilisée pour satisfaire la demande alimentaire s'élevait à 182 milliers de tonnes, tandis que les exportations nettes (graines et huiles) représentaient l'équivalent de 816 milliers de tonnes d'huile (Prolea, 2006). Le total de ces deux usages correspond à l'équivalent de 934 millions de tonnes de biodiesel qui pourraient donc être produits et utilisés dans les carburants. Ce supplément de biodiesel correspond à la quantité qui, en 2015, représenterait environ $2,6 \%$ de la quantité de gazole utilisée dans les transports routiers.

\subsection{Résultats}

\subsubsection{Sur les assolements}

Le premier résultat de notre simulation est comme on pouvait s'y attendre une augmentation des surfaces en colza et tournesol quand le niveau d'incorporation exigé augmente. Cette augmentation se fait au détriment des céréales (blé et orges principalement) et des protéagineux. L'augmentation de la part de la superficie en colza est notable, elle passe de $8 \%$ pour le scénario de référence à un taux de $23 \%$ dans le scénario S3 (tableau 12). On remarque que la jachère nue est égale à $10 \%$ dans le scénario de référence, et ceci en dépit du fait qu'une partie de la jachère PAC est cultivée en cultures énergétiques. Ceci s'explique par le fait que dans nos données de base, un nombre non négligeable d'exploitations présente une superficie de jachère totale supérieure aux $10 \%$ de jachère PAC (sans doute pour des raisons agronomiques : accès et tailles des parcelles, terres peu productives). L'augmentation de la superficie en colza et tournesol ne se fait donc que très partiellement au détriment de la jachère dans nos simulations.

Le second résultat est qu'il n'est pas possible d'atteindre $10 \%$ d'incorporation, dans l'hypothèse de maintien des exportations et de l'usage alimentaire actuels, et dans le cadre des systèmes de production envisagés dans notre modèle. Dans la variante E1, le scénario S4 ne trouve pas de solution dans notre modèle. Dans la variante E2 en revanche, il est possible d'atteindre $10 \%$ d'incorporation. 
L'analyse des résultats détaillés montre des différences entre les régions. Celles qui, dans le scénario de référence, ont déjà une plus grande proportion de colza dans leur assolement (Centre, Poitou-Charentes, Bourgogne, Lorraine) voient la part de celui-ci augmenter moins rapidement avec l'accroissement de la demande de biodiesel, que les régions qui disposent d'une plus grande diversité de têtes d'assolement et en cultivent moins dans le scénario de référence. Ainsi en Champagne, Picardie, Ile-de-France, Haute-Normandie, le colza se substitue progressivement, à la betterave, à la luzerne ou au pois protéagineux. Les différences entre les régions s'estompent progressivement, au fur et à mesure que le taux d'incorporation s'accroît, et, dans le scénario S2, la superficie en colza représente plus du quart des superficies dans toutes les régions considérées, et plus de $30 \%$ dans bien des cas.

Les mêmes scénarios ont été simulés sous l'hypothèse de mise à zéro des exportations et de la demande intérieure en huile alimentaire (variante E2). Les résultats régionaux sont rapportés dans le tableau 14. On constate que le scénario S4 trouve à présent une solution dans le modèle, impliquant que le taux d'incorporation de $10 \%$ peut dans ce cas être atteint. Ce taux d'incorporation implique cependant que près du tiers des superficies est alloué en colza dans la plupart des régions de production. Et c'est tout de même de 23 à $28 \%$ des superficies de chaque région qu'il faudrait consacrer au colza pour atteindre en $20157 \%$ d'incorporation (S2).

Nous nous sommes intéressés également à la place que prendraient les superficies en colza, dans les exploitations qui en produisent, qui ne représentent pas, rappelons-

Tableau 12. Répartition de la surface entre cultures (en \%)

\begin{tabular}{lcrrr}
\hline \multicolumn{5}{c}{ Variante E1 maintien des exportations et de la consommation alimentaire } \\
\hline \multicolumn{1}{c}{ Scénarios } & SRef & S1 & S2 & S3 \\
\hline Céréales & 67 & 63 & 61 & 57 \\
Protéagineux & 5 & 3 & 3 & 2 \\
Betterave & 3 & 3 & 3 & 2 \\
Colza & 8 & 16 & 19 & 23 \\
Tournesol & 3 & 5 & 5 & 7 \\
Jachère nue & 10 & 7 & 7 & 6 \\
Autres & 3 & 3 & 3 & 3 \\
\hline
\end{tabular}

Tableau 13. Part de la surface cultivée en colza par région-Variante E1 (en \%)

\begin{tabular}{lcccc}
\hline \multicolumn{6}{c}{ Variante E1 maintien des exportations et de la consommation alimentaire } \\
\hline \multicolumn{1}{c}{ Scénarios } & SRef & S1 & S2 & S3 \\
\hline Centre & 19 & 27 & 31 & 36 \\
Champagne & 12 & 24 & 28 & 38 \\
Picardie & 10 & 23 & 29 & 38 \\
Poitou-Charentes & 19 & 25 & 27 & 34 \\
Bourgogne & 18 & 28 & 31 & 35 \\
IDF & 15 & 27 & 31 & 38 \\
Haute-Normandie & 13 & 24 & 30 & 37 \\
Lorraine & 21 & 30 & 34 & 38 \\
Nord-Pas-de-Calais & 12 & 19 & 23 & 35 \\
\hline
\end{tabular}


le, la totalité des exploitations de notre échantillon. La part de la superficie en colza dans les exploitations qui en produisent est donc plus élevée que la part de cette même superficie rapportée à la surface totale cultivée, observée en moyenne dans l'ensemble de notre échantillon.

On voit ainsi que si l'objectif de 5,75\% d'incorporation (S1-VarE1) semble encore compatible avec des pratiques agronomiques satisfaisantes dans la majorité des exploitations, ce n'est plus le cas au-delà de ce taux d'incorporation.

Ce résultat est différent selon les régions, avec certaines d'entre elles qui seraient plus particulièrement concernées par un retour fréquent du colza dans les successions culturales : il s'agit en particulier des régions Centre, Bourgogne, Lorraine et Ile-deFrance.

\subsubsection{Sur les prix de revient et la compétitivité du biodiesel}

Les courbes présentées dans le graphique 1 (voir supra) permettent d'observer l'impact de l'augmentation de la demande en biodiesel sur le prix d'opportunité du colza. Nous avons simulé une croissance régulière de la demande en biodiesel. Rappelons que le prix des oléagineux n'a pas été introduit comme valeur exogène dans le modèle. La valeur duale de la contrainte qui oblige à produire une quantité de colza représente le prix minimum qu'il serait nécessaire d'offrir aux agriculteurs pour qu'ils produisent exactement cette quantité.

Tableau 14. Part de la surface cultivée en colza par région-Variante E2 (en \%)

\begin{tabular}{lccccc}
\hline \multicolumn{7}{c}{ Variante E2 suppression des exportations et de la consommation alimentaire } \\
\hline Centre & SRef & S1 & S2 & S3 & S4 \\
Champagne & 12 & 22 & 25 & 30 & 32 \\
Picardie & 11 & 15 & 20 & 27 & 31 \\
Poitou & 4 & 14 & 19 & 27 & 31 \\
Bourgogne & 18 & 18 & 22 & 26 & 29 \\
IDF & 9 & 23 & 24 & 30 & 33 \\
Haute-Normandie & 10 & 20 & 23 & 31 & 33 \\
Lorraine & 10 & 16 & 20 & 28 & 32 \\
Nord & 11 & 24 & 27 & 33 & 36 \\
\end{tabular}

Tableau 15. Part moyenne de la surface en colza dans la SAU des exploitations qui en produisent

\begin{tabular}{lcccc}
\hline \multicolumn{5}{c}{ Variante E1 maintien des exportations et de la consommation alimentaire } \\
\hline \multicolumn{1}{c}{ Scénarios } & SRef & S1 & S2 & S3 \\
\hline $\begin{array}{l}\text { Part de la surface en colza dans la surface cultivable } \\
\text { des exploitations produisant du colza }\end{array}$ & $16 \%$ & $26 \%$ & $30 \%$ & $36 \%$ \\
$\begin{array}{l}\text { Part de l'effectif d'exploitations dépassant 25\% } \\
\text { de leur surface cultivable en colza }\end{array}$ & $17 \%$ & $48 \%$ & $61 \%$ & $87 \%$ \\
\hline
\end{tabular}


Tableau 16. Part de l'effectif d'exploitations productrices de colza faisant plus de $25 \%$ de leur surface cultivable en colza (en \%)

\begin{tabular}{lcccc}
\hline \multicolumn{5}{c}{ Variante E1 maintien des exportations et de la consommation alimentaire } \\
\hline Centre & SRef & S1 & S2 & S3 \\
Champagne & 19 & 55 & 69 & 84 \\
Picardie & 7 & 33 & 53 & 94 \\
Poitou & 2 & 40 & 59 & 96 \\
Bourgogne & 22 & 38 & 43 & 79 \\
IDF & 25 & 65 & 74 & 76 \\
Normandie & 6 & 48 & 69 & 92 \\
Lorraine & 4 & 47 & 62 & 95 \\
Nord & 31 & 76 & 86 & 95 \\
\hline
\end{tabular}

Nos résultats complètent ceux obtenus dans d'autres travaux utilisant une version précédente du modèle, en particulier parce que ces derniers portaient sur des demandes plus faibles en biodiesel se traduisant par une production d'oléagineux à usage énergétique essentiellement sur jachère (Rozakis et Sourie, 2005) ou dont l'usage énergétique se ferait au détriment de l'usage alimentaire (Sourie et al., 2005). L'approche retenue ici nous permet d'analyser les conséquences d'une demande plus élevée qui, comme nous l'avons vu, devrait se traduire par des modifications importantes des systèmes de culture et nécessiterait une hausse du prix payé aux producteurs.

On observe ainsi que pour un niveau d'incorporation de $7 \%$ (S2), le prix minimum auquel les agriculteurs produiraient les quantités de colza nécessaires serait d'environ 280 euros/tonne dans le cas d'un prix des céréales bas (variante P1), et de 400 euros/tonne dans un scénario de prix des céréales élevés (variante P2). Ces chiffres passent respectivement à 340 euros/tonne et 500 euros/tonne si l'objectif d'incorporation est porté à $8 \%$.

Le graphique 1 met en évidence deux phénomènes, d'une part la forte croissance du prix dual quand les niveaux d'incorporation augmentent et, d'autre part, la forte sensibilité de ce prix à celui des céréales. Ceci s'explique par ce que nous avons vu précédemment: c'est en grande partie en substitution aux céréales que se fait le développement des surfaces en colza et c'est, dans la plupart des exploitations et des régions, par des changements dans l'itinéraire technique, impliquant une hausse des coûts et des baisses de rendements, que cette croissance pourrait se réaliser.

Le prix ainsi obtenu pour les cultures oléagineuses entrant dans la composition du biodiesel nous permet de calculer le prix de revient minimal du biodiesel dans les différents scénarios d'incorporation étudiés, en prenant en compte par ailleurs les coûts de transformation et ceux des inputs nécessaires (méthanol) et en déduisant la valorisation des co-produits (glycérine et tourteaux). Ce prix de revient minimal comparé au prix du gazole permet de discuter de la compétitivité du biodiesel par rapport au carburant auquel il se substitue. 
Le graphique 2 présente les résultats obtenus dans les deux scénarios de prix de céréales élevé (courbes en noir) et bas (courbes en gris).

Les courbes en traits pleins indiquent pour différents niveaux d'incorporation (notés sur l'axe des ordonnées) le prix de revient minimal du biodiesel (noté sur l'axe des abscisses). Est indiqué, également sur l'axe des abscisses, l'équivalent en terme de prix du pétrole de ce prix du biodiesel (en tenant compte de la relation prix du gazole/ prix du pétrole et du pouvoir calorifique différent du biodiesel par rapport au gazole ${ }^{6}$ ). Les courbes en pointillé incluent dans le calcul la défiscalisation dont bénéficie actuellement le biodiesel.

On voit ainsi, par exemple, sur la courbe en noir (donc dans un scénario de prix des céréales élevés) que pour un niveau d'incorporation de $5,75 \%$ (S1), le biodiesel serait compétitif pour un prix du pétrole situé au-delà de 130 \$/baril. La défiscalisation dont bénéficie le biodiesel (courbe en pointillés noirs) réduit ce seuil à $80 \$ /$ baril de pétrole. Dans un scénario de prix des céréales bas (courbes en gris), ces chiffres seraient respectivement de $95 \$ /$ baril et $50 \$ /$ baril.

Le graphique 2 met en évidence que la compétitivité du biodiesel diminue fortement lorsque le niveau d'incorporation exigée augmente.

Pour un niveau d'incorporation exigé de $7 \%$ (S2), le prix du pétrole doit se situer au-delà de 165 \$/baril si les prix des céréales sont élevés et en l'absence d'aide de l'Etat.

Figure 2. Prix de revient et compétitivité du biodiesel par rapport au pétrole pour différents niveaux d'incorporation

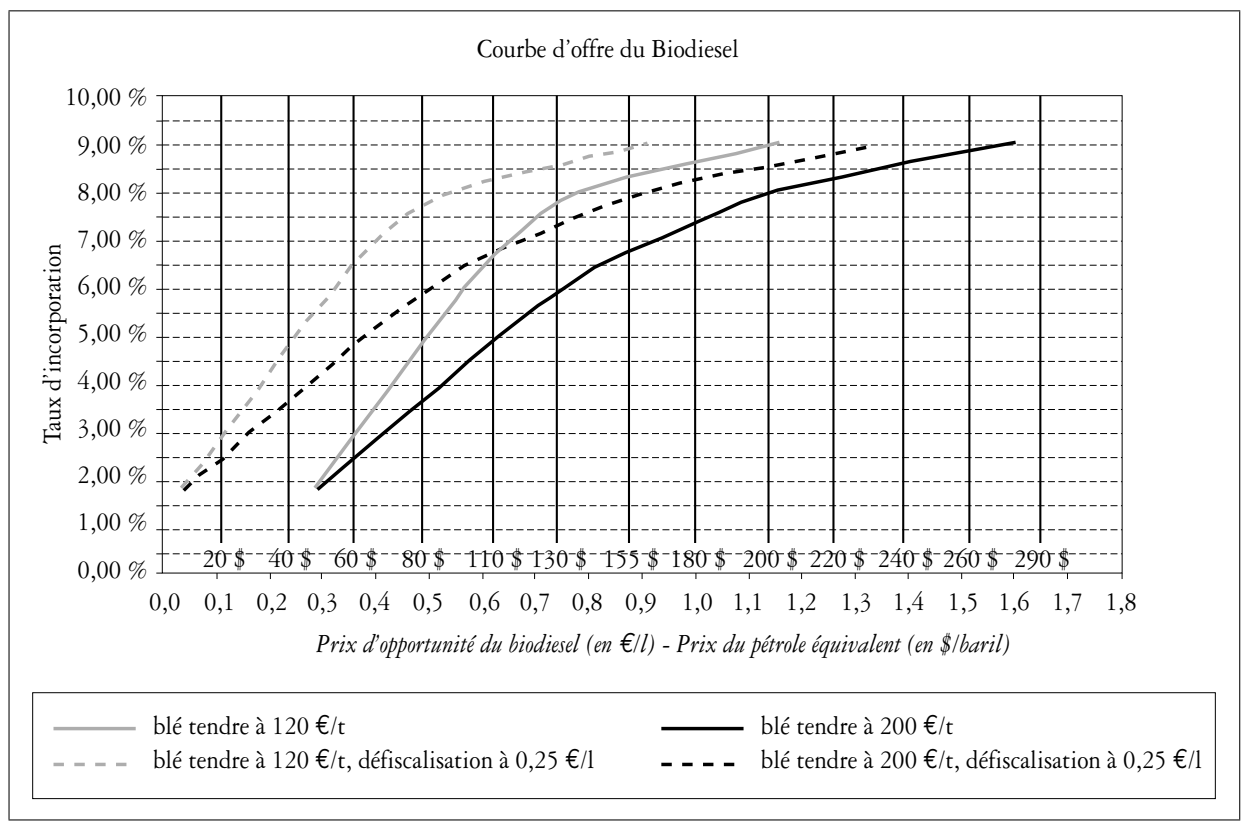

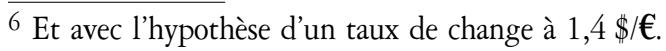


Dans un scénario de prix des céréales bas (courbe en gris), le seuil de compétitivité diminue à $115 \$$ / baril. Les résultats de la même simulation avec un prix du tourteau de colza de $150 € /$ t (au lieu de $110 € / t$ ) montrent que pour ce même niveau d'incorporation (et dans le scénario de prix des céréales élevés) la compétitivité s'établirait pour un prix du pétrole de 155 \$/baril. Ces résultats montrent donc également que la compétitivité du biodiesel par rapport au gazole dépend, bien entendu, du prix de ce dernier et du taux de change, mais également fortement des autres éléments du contexte économique que sont ici le prix des céréales et le prix du co-produit principal, le tourteau.

\section{Conclusion}

Le développement des carburants d'origine agricole en Europe est le résultat d'une politique dont les objectifs sont indiscutablement très importants : lutter contre le réchauffement climatique par la réduction des émissions de gaz à effet de serre, diversifier les approvisionnements énergétiques en réduisant la dépendance au pétrole. Les impacts attendus d'un développement des biocarburants sont relativement faibles par rapport à ces deux objectifs, puisqu'on estime qu'une incorporation de $10 \%$ de biocarburants dans les carburants utilisés dans les transports routiers ferait diminuer les importations de pétrole de $3 \%$ et les émissions de gaz à effets de serre de seulement $1 \%$, les transports représentant actuellement environ le quart des émissions globales. Mais il est certain que même minimes ces impacts positifs ne sont pas à négliger (Jacquet et al., 2007).

La politique française se situe dans la même perspective que la politique européenne, mais avec des objectifs renforcés par rapport à celle-ci: 3,5\% d'incorporation de biocarburants dans les carburants utilisés dans les transports routiers devront être atteints en 2008, 7 \% d'incorporation en 2010 (au lieu des 5,75 \% fixés au niveau européen), $10 \%$ en 2015. Les instruments mis en place depuis 2005 ont permis à la France d'atteindre l'objectif fixé pour la première fois en 2006.

Le but de notre travail était de mesurer les conséquences que pourrait avoir cette politique sur les systèmes de production agricole les plus directement concernés, afin de fournir des éléments de réflexion pouvant contribuer à l'évaluation des choix publics qui sont faits actuellement.

Nous avons montré qu'un objectif d'incorporation de $7 \%$, s'il devait se réaliser en 2015 sur la base d'une production agricole hexagonale, conduirait à une croissance très importante des superficies cultivées en colza, celles-ci devant alors couvrir dans les principales régions de production françaises près de $30 \%$ des superficies agricoles. Cette augmentation se ferait au détriment des surfaces en céréales, en protéagineux et, de manière indirecte, par la remise en culture d'une partie de la jachère. La grande majorité des exploitations de grandes cultures devrait cultiver du colza sur plus du quart de leurs surfaces. Peu de travaux agronomiques existent à notre connaissance sur les conséquences environnementales d'une telle modification des systèmes. L'augmentation des traitements phytosanitaires est néanmoins probable du fait de deux effets augmentant la pression parasitaire et la difficulté de gérer l'apparition des 
maladies: le retour fréquent du colza sur une même parcelle, la présence d'une superficie de colza importante en proportion des autres cultures dans une même région.

Par ailleurs, dans une simulation de l'effet de différents scénarios économiques sur la pollution par les nitrates de la nappe phréatique dans une région française et une région allemande (Alsace et Baden), Graveline (2006) montre que le développement des biocarburants serait le scénario qui augmenterait le plus la pollution, du fait de l'augmentation du colza dans les assolements.

Nos résultats montrent aussi qu'il serait impossible d'atteindre $10 \%$ d'incorporation même avec un tel changement de pratiques, sauf à réduire les exportations ou en ayant recours à des importations. La France et l'Allemagne, qui sont les deux premiers producteurs européens de colza, ont des objectifs de développement de la consommation de biodiesel qui sont, pour l'un comme l'autre, demandeurs d'une production d'oléagineux au-delà de leurs capacités actuelles, et qui devront certainement être satisfaits en partie par des importations en provenance de pays tiers. Mais beaucoup de pays du monde ont des programmes de développement de la consommation de biocarburants qui vont certainement fortement peser sur le marché mondial des huiles et des oléagineux.

Une autre conclusion de notre travail est que l'augmentation du prix de colza nécessaire pour inciter les producteurs français à produire les quantités requises par les objectifs d'incorporation serait considérable, surtout pour des niveaux d'incorporation situés au-delà de $5 \%$. Nous avons simulé deux hypothèses de prix des céréales et nous observons une grande sensibilité de nos résultats à ce prix, du fait de la substitution entre cultures dans l'utilisation des sols.

Nos résultats montrent enfin que, pour un prix du pétrole donné, la compétitivité du biodiesel pourrait diminuer fortement à mesure que les exigences d'incorporation augmenteront. Le niveau de défiscalisation nécessaire pour compenser la différence de compétitivité entre biocarburants et carburants classiques devrait donc augmenter et les dépenses publiques également sous le double effet de cette baisse de compétitivité et de l'augmentation importantes des volumes agréés. Une augmentation du prix du pétrole plus forte que celle des produits agricoles pourrait cependant modifier ce résultat.

Une évaluation des impacts environnementaux globaux du développement des biocarburants reste à faire, qui prendrait en compte les effets provenant des changements dans les utilisations des sols et les itinéraires techniques. Notre modèle peut être amélioré pour y contribuer, en incluant des itinéraires techniques et des systèmes de cultures différents de ceux qui sont actuellement pratiqués par les agriculteurs. C'est aussi, plus largement, pour analyser les conséquences des changements de politiques agricoles, énergétiques et environnementales qui seront mises en place dans les années à venir que seront nécessaires des modèles économiques capables de simuler les impacts sur les choix de productions, les pratiques agronomiques des agriculteurs et leurs conséquences environnementales. 


\section{Bibliographie}

ADEME/DIREM (2002) Bilans énergétiques et gaz à effet de serre des filières de production de biocarburants, Rapport d'après les travaux d'Ecobilan Price Waterhouse Coopers, novembre, p. 132, rapport d'annexes, p. 39, note de synthèse, $17 \mathrm{p}$.

AGRESTE (2006) Tableaux standards 2004 RICA France, Chiffres et données, série Agriculture 177, $180 \mathrm{p}$.

Bulletin officiel des douanes (2006) Produits énergétiques - Taxe générale sur les activités polluantes - prélèvement sur les carburants, n 6665 du 3 février, 34 p.

CETIOM (2002) Colza d'hiver, Cabier technique, mai, 36 p.

Commission européenne (2007) Rapport sur les progrès accomplis en matière de biocarburants et des autres carburants renouvelables dans les Etats-Membres de l'Union européenne, COM (2006), 845 final, 10 janvier, 18 p.

Commission européenne (2003) European energy and transport - Trends to 2030, Direction générale de l'énergie et des transports, 30 janvier, 22 p.

Curran L., Trigg S., McDonald A., Astiani D., Hariono Y., Siregar P., Caniago I. and Kasischke E. (2004) Lowland forest loss in protected areas of Indonesia Borneo, Science 303, 1000-1003.

De Gorter H., Just D.R. (2007) The economics of US ethanol import tariffs with a consumption mandate and tax credit, Cornell University, Working Paper 21, $29 \mathrm{p}$.

DIREM (2006) L'industrie pétrolière, 65 p.

Doornbosch R., Steenblik R. (2007) Biofuels: Is the cure worse than the disease?, Roundtable on Sustainable Development, Paris, OECD, September 11-12, 57 p.

Elobeid A., Tokgoz S., Hayes D., Babcock B. and Hart C. (2006) The long-run impact of corn-based ethanol on the grain, oilseed, and livestock sectors: A preliminary assessment, CARD Briefing paper 06-BP 49, 15 p.

EUCAR, CONCAWE, JRC Ispra (2006) Well-to-wheels analysis of future automotive fuels and powertrains in the European context Well-to-Wheels Report version May, http://ies.jrc.cec.eu.int/WTW, 88 p.

European Commission (2007a) Commission staff working document, accompanying document to the Biofuels progress report, Report on the progress made in the use of biofuels and other renewable fuels in the Member States of the European Union, $\operatorname{COM(2006)~} 1721$ final, January, 28 p.

European Commission (2007b) Prospects for agricultural markets 2006-2013, Report, January, 36 p. 
European Commission (2007c) Public consultation «Biofuel issues in the new legislation on the promotion of renewable energy », Stakeholders' contributions, bttp:/lec.europa.eulenergy/res/consultation/biofuels_en.htm

Farrell A.E., Plevin R.J., Turner B.T., Jones A.D., O'Hare M. and Kammen D.M. (2006) Ethanol can contribute to energy and environmental goals, Science 311(5760), 506-508.

Gardner B. (2007) Fuel ethanol subsidies and farm price support, Journal of Agricultural E Food Industrial Organization 5 (2), article 4.

Gohin A. (2007) Impacts of the European bio-fuel policy on the farm sector: A general equilibrium assessment, Paper presented at the conference «Bio-Fuels, Food and Feed Tradeoffs » sponsored by Farm Foundation and USDA, April 12-13, St Louis, Missouri.

Gosse G., Cormeau J. (2007) Biocarburants de deuxième génération : semer aujourd'hui les carburants de demain, Le Déméter 2008, 225-302.

Graveline N. (2006) Integrating economic with groundwater modelling for developing long term nitrate concentration scenarios in a large aquifer, Paper presented at the International symposium Darcy 2006 «Aquifer Systems Management », Bureau de recherches géologiques et minières, Dijon, 30 mai-1 ${ }^{\text {er }}$ Juin.

Guindé L., Millet G., Bamière L. et Jacquet F. (2007) Analyse de l'impact d'une nouvelle réforme de la PAC et d'une politique de développement des biocarburants sur les exploitations de grande culture, Prospective "Agriculture 2013 », Résultats des travaux quantitatifs, Modèle OSCAR, Rapport d'étude, Paris, $39 \mathrm{p}$.

Guindé L., Millet G. et Sourie J.-C. (2004) Analyse micro-économique de scénarios de réforme de l'OCM sucre à l'aide d'un modèle d'offre agricole, Rapport d'étude, Paris, 83 p.

Hill J. (2007) Environmental costs and benefits of transportation biofuel production from food and lignocellulose-based energy crops. A review, Agronomy for Sustainable Development 27, 1-12.

Jacquet F., Bamière L., Bureau J.-C., Guindé L., Millet G. et Tréguer D. (2007) Les enjeux du développement des biocarburants dans l'Union européenne, INRA Sciences sociales 2-3, $6 \mathrm{p}$.

J.O. (2005) Loi n 2005-781 du 13 juillet 2005 de programme fixant les orientations de la politique énergétique, 14 Juillet, 3 p.

Lefevre A. (2005) Modélisation et évaluation de l'impact environnemental et des performances agronomiques et économiques des systèmes de culture : application aux grandes cultures annuelles de Picardie, Mémoire DAA Agro-environnement ENSA-M, Montpellier.

Ministère de l'Industrie (2007) Liste des unités de production de biocarburants ayant reçu un agrément après appel d'offres communautaire, DGEMP-DIREM, 22 octobre, 2 p. bttp://www.industrie.gouv.fr/energie/renou/biomasselagrements-biocarburants.pdf. 
Msangi S., Sulser T., Rosegrant M., Valmonte-Santos R. and Ringler C. (2006) Global scenarios for biofuels: Impacts and implications, International Food Policy Research Institute (IFPRI), 16 p.

OCDE (2006) Incidences de la croissance de la production des biocarburants sur les marchés agricoles, Rapport d'étude, AGR/CA/APM(2005)24/FINAL, 60 p.

ONIGC (2006) Gel industriel et cultures énergétiques, Bilan 2005/2006 et Perspectives 2006/2007, décembre, 80 p.

PROLEA (2006) De la production à la consommation France-Europe-Monde, statistiques des oléagineux et protéagineux, huiles et protéines végétales, 20052006, 136 p.

Rajagopal D., Sexton S.E., Roland-Holst D. and Zilberman D. (2007) Challenge of biofuel: Filling the tank without emptying the stomach? Environmental Research Letters 2, $9 \mathrm{p}$.

Rozakis S., Sourie J.-C (2005) Micro-economic modelling of biofuel system in France to determine tax exemption policy under uncertainty, Energy Policy 33, 171-182.

Schmidhuber J. (2007) Impact of an increased biomass use on agricultural markets, prices and food security: A longer-term perspective, Discussion paper, Wageningen Seminar on Bioenergy, March 2.

Sourie J.-C., Tréguer D. et Rozakis S. (2005) L'ambivalence des filières biocarburants, INRA Sciences Sociales 2, décembre, $8 \mathrm{p}$.

Tokgoz S., Elobeid A., Fabiosa J., Hayes D., Babcock B., Yu T., Dong F., Hart C. and Beghin J. (2007) Emerging biofuels: Outlook of effects on US grain, oilseed, and livestock markets, CAD, Iowa State, Staff Report 07-SR 101, May, 57 p.

Tyner W.E. (2007) Policy alternatives for the future biofuels industry, Journal of Agricultural \& Food Industrial Organization 5(2), Article 2.

Von Braun J. (2007) When food makes fuel: The promises and challenges of biofuels, Keynote address at the Crawford Fund Annual Conference, Australia, August 15. 
